\title{
A FORMAÇÃO HISTÓRICO-TERRITORIAL DO MATO GROSSO, AS TRANSFORMAÇÕES E IMPACTOS DECORRENTES DA EXPANSÃO DA SOJA ${ }^{1}$
}

\author{
Alessandra da Silva Lobato ${ }^{2}$ \\ Danilo Raiol de Carvalho ${ }^{3}$ \\ Marcela Alves da Silva ${ }^{4}$ \\ Miguel Sá de Souza Brito 5
}

\section{Resumo}

O presente artigo busca compreender como ocorreu o processo de formação históricoterritorial do Estado do Mato Grosso. Para compreender tal processo torna-se necessário entender este espaço desde o período colonial aos dias atuais. Busca-se analisar o panorama econômico deste Estado no contexto nacional, enfocando a expansão do complexo sojeiro em áreas de fronteira agrícola nacional. Além disso, destacamos, também, os impactos ambientais e socioeconômicos que a atividade sojeira tem provocado no espaço, tanto o espaço rural quanto o espaço urbano. Observa-se que estes impactos têm afetado diretamente os diferentes atores sociais que de alguma forma participam do processo.

Palavras-chave: Mato Grosso; Soja; Logística; Impactos.

\section{Summary}

This article seeks to understand how the process was the socio-territorial state of Mato Grosso. To understand this process it is necessary to understand this space since the colonial period to the present day. It analyzes the economic outlook of the State in the national context, focusing on the expansion of the complex soy growers in areas of national agricultural frontier. Moreover, we note also the environmental and socioeconomic impacts that the activity has caused soy growers in space, both rural and urban areas. It is observed that these impacts have directly affected the different social actors that somehow participate in the process.

Keywords: Mato Grosso; Soy; Logistics; Impacts.

\footnotetext{
${ }^{1}$ Artigo apresentado na disciplina Geografia da Amazônia do curso de Geografia da Universidade Federal do Pará, ministrada pela professora Dra . Maria Goretti da Costa Tavares.

${ }^{2}$ Graduanda do curso de Geografia da UFPA. E-mail: alessandrageo19@yahoo.com.br

${ }^{3}$ Graduando do curso de Geografia da UFPA. E-mail: danilo.carvalho@ifch.ufpa.br

${ }^{4}$ Graduanda do curso de Geografia da UFPA. E-mail: marcelaalves2006@yahoo.com.br

${ }^{5}$ Graduando do curso de Geografia da UFPA. E-mail: miguelssb@gmail.com
} 


\section{Introdução}

O presente artigo tem como objetivos compreender como se deu o processo de formação histórico-territorial do Estado do Mato Grosso, já que este Estado tem passado por uma série de transformações sejam elas políticas, econômicas, sociais e ambientais. Para compreender tal processo, foram levantadas informações desde o período colonial aos dias atuais, destacando o panorama econômico do Estado no contexto nacional, enfocaremos a expansão do complexo sojeiro em áreas de fronteira agrícola nacional. Buscaremos compreender, também, como se tem configurado a logística e a infraestrutura do complexo sojeiro neste Estado. Além disso, apontaremos as principais transformações que os impactos ambientais e socioeconômicos deixam neste espaço seja no espaço urbano, seja no espaço rural.

Observa-se que a atividade sojeira tem proporcionado transformações no espaço matogrossense, devido à expansão do meio técnico-científico-informacional, Santos (1979), o que proporcionado mudanças significativas neste Estado.

Nota-se que esta reestruturação produtiva da agropecuária, Elias (2006), tem proporcionado uma expansão dos sistemas de objetos e dos sistemas de ações, pois "De um lado, os sistemas de objetos condicionam a forma como se dão as ações e, de outro lado, o sistema de ações leva à criação de objetos novos ou se realiza sobre objetos preexistentes. É assim que o espaço encontra sua dinâmica e se transforma”. (SANTOS, 2002, p.63)

Para desenvolver o presente trabalho foram realizadas pesquisas bibliográficas de autores de renome, para adquirir embasamento teórico sobre o assunto desenvolvido, análise de dados estatísticos, comparativos, obtidos em sites especializados, artigos, trabalhos e livros voltados para a área, com o intuito de fornecer aos leitores recursos suficientes para um melhor entendimento do trabalho.

O artigo está estruturado em duas partes, além da introdução e das considerações finais. Na primeira parte trataremos da formação histórico-territorial do Estado de Mato Grosso, no período Colonial, Imperial e Republicano, período este no qual ocorreu a divisão do Estado do Mato Grosso, em dois Estados: Mato Grosso e Mato Grosso do Sul.

Já na segunda parte trataremos do complexo sojeiro, que envolve a logística e a infraestrutura necessária para a manutenção do mesmo, além disso, destacarmos, também, os impactos ambientais e socioeconômicos decorrentes desta atividade. 


\section{1- Formação Histórico-Territorial do Estado do Mato Grosso}

O território brasileiro possui um processo diferenciado de ocupação, com características próprias, e na região Centro-Oeste não poderia ter sido diferente. Após o descobrimento dos Reinos de Portugal e Espanha, ocorreram divergências entre a localização das divisas das terras, foi a partir deste momento que em 7 de julho de 1494, em Tordesilhas foi modificada a linha definida neste tratado para 1.786,3 quilômetros de Cabo Verde, como podemos observar na figura 1 . No entanto, devido ao tamanho da linha demarcadora ser muito extensa, e sem como saber por onde ela realmente passava esse tratado não entrou em execução. Com isso em 13 de janeiro de 1750 foi assinado pelos dois reinos outro tratado, o Tratado de Limites de Conquistas, observe a figura 2, conhecido como Tratado de Madri, com base no uti possidets, formando uma nova configuração para o território do Brasil colônia.

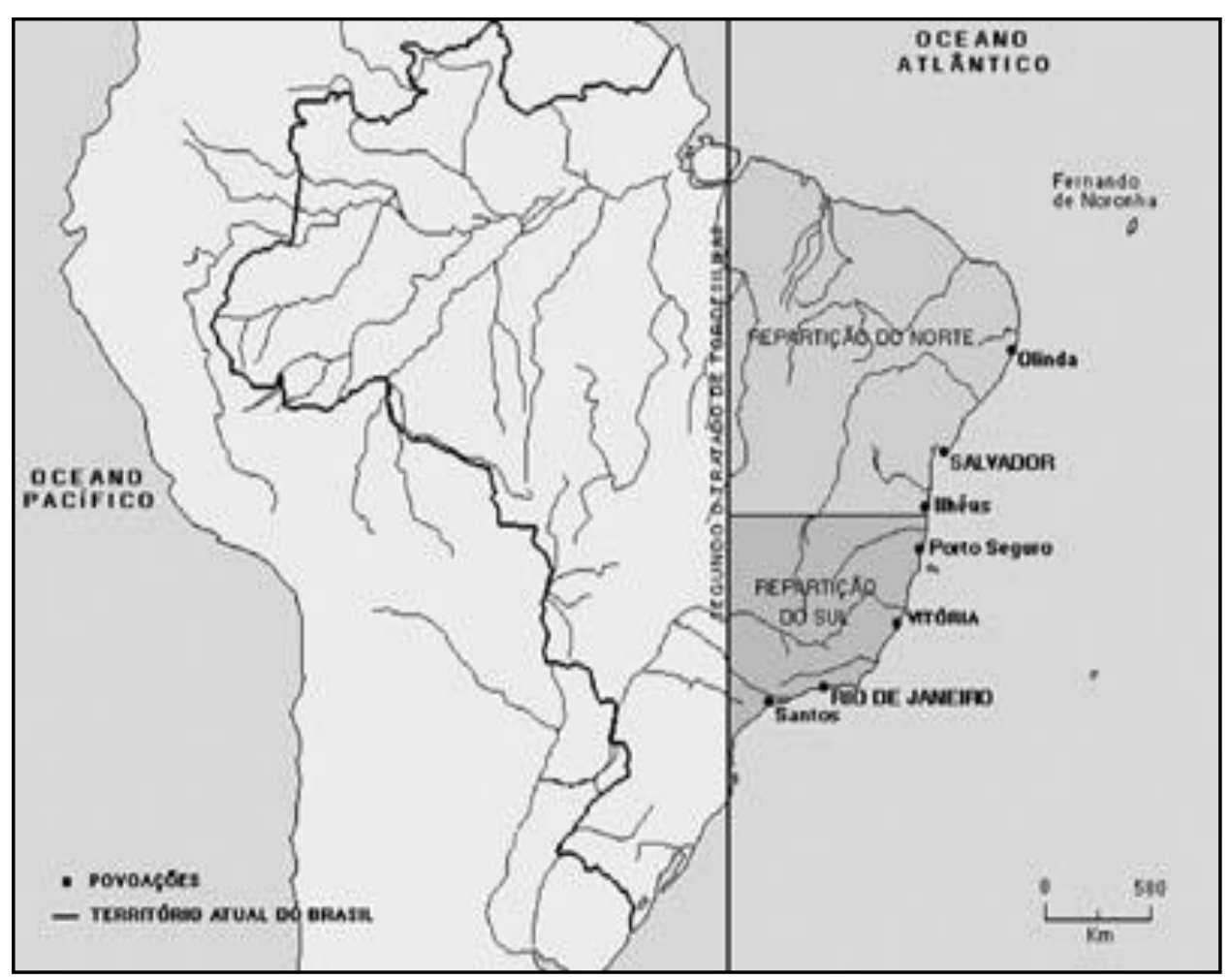

Figura 1: Mapa do Tratado de Tordesilhas.

Fonte: www2.mre.gov.br 


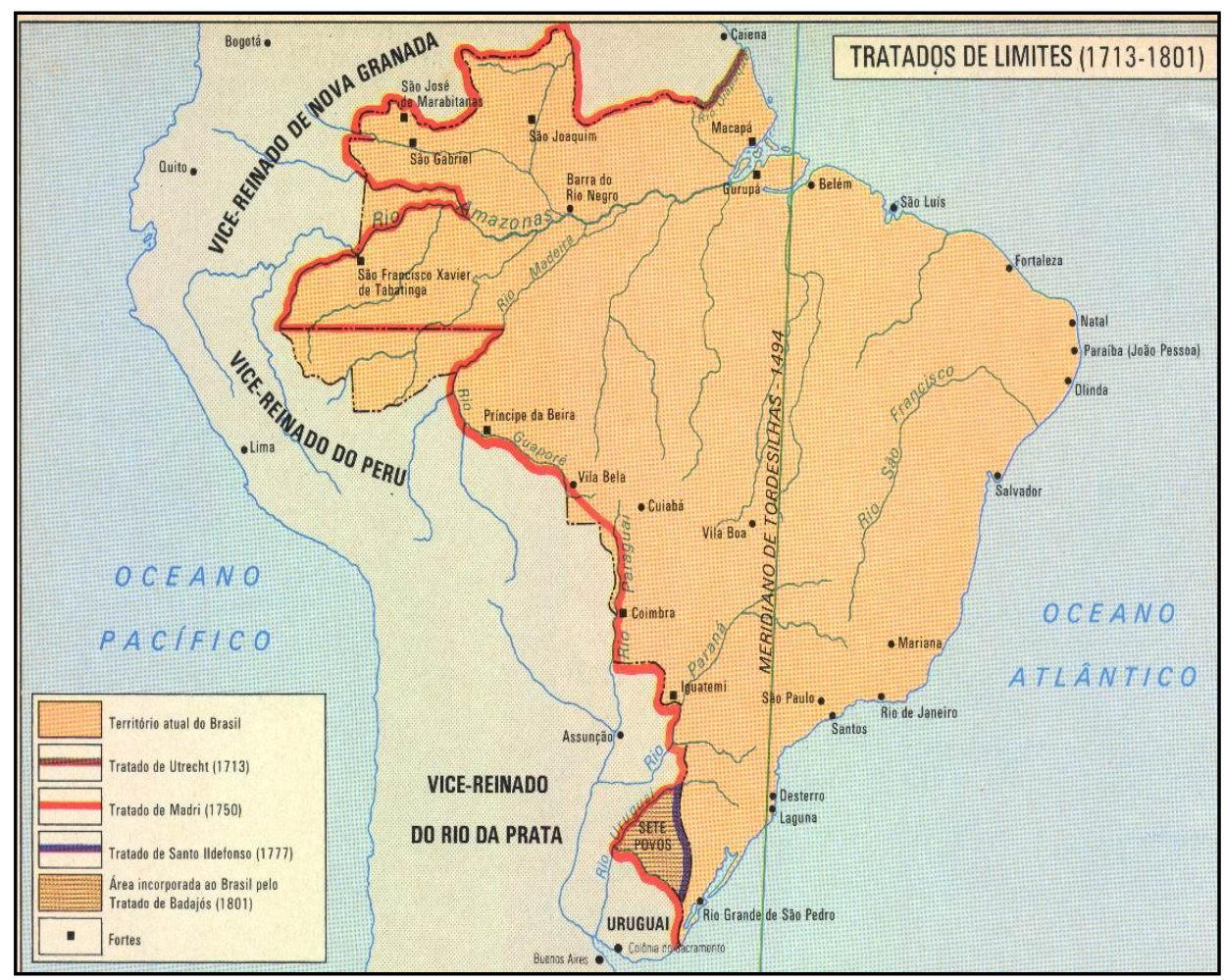

Figura 2: Mapa do Tratado de Limites de Conquista. Fonte: www2.mre.gov.br

A região conhecida como Mato Grosso era subordinada à capitania de São Paulo; no entanto, com a entrada das bandeiras, observe a figura 3, e a descoberta do ouro em Cuiabá, foi que a Metrópole Portuguesa, por meio da carta Régia de 9 de maio de 1748 criava a então, capitania do Mato Grosso, observe a figura 4.

Esta capitania foi criada por uma questão de segurança devido a relação de divergência na fixação dos limites da região, por isso a capital da Capitania foi Vila Bela da Santíssima Trindade, que ficava nas margens do rio Guaporé e não em Cuiabá como queria o primeiro Governador Antônio Rolim de Moura Tavares.

A economia no Período Colonial da capitania do Mato Grosso era denominada agroexportadora onde predominava a pecuária extensiva paralela a atividade mineradora, que foi a grande responsável pelo povoamento do Mato Grosso, e que proporcionou a ocupação urbana na área de Cuiabá, e que proporcionou também, a partir de 1736, a criação de outros pequenos povoados como Diamantino, São Francisco, Santana, Rosário, Coxim e Camapuã. 


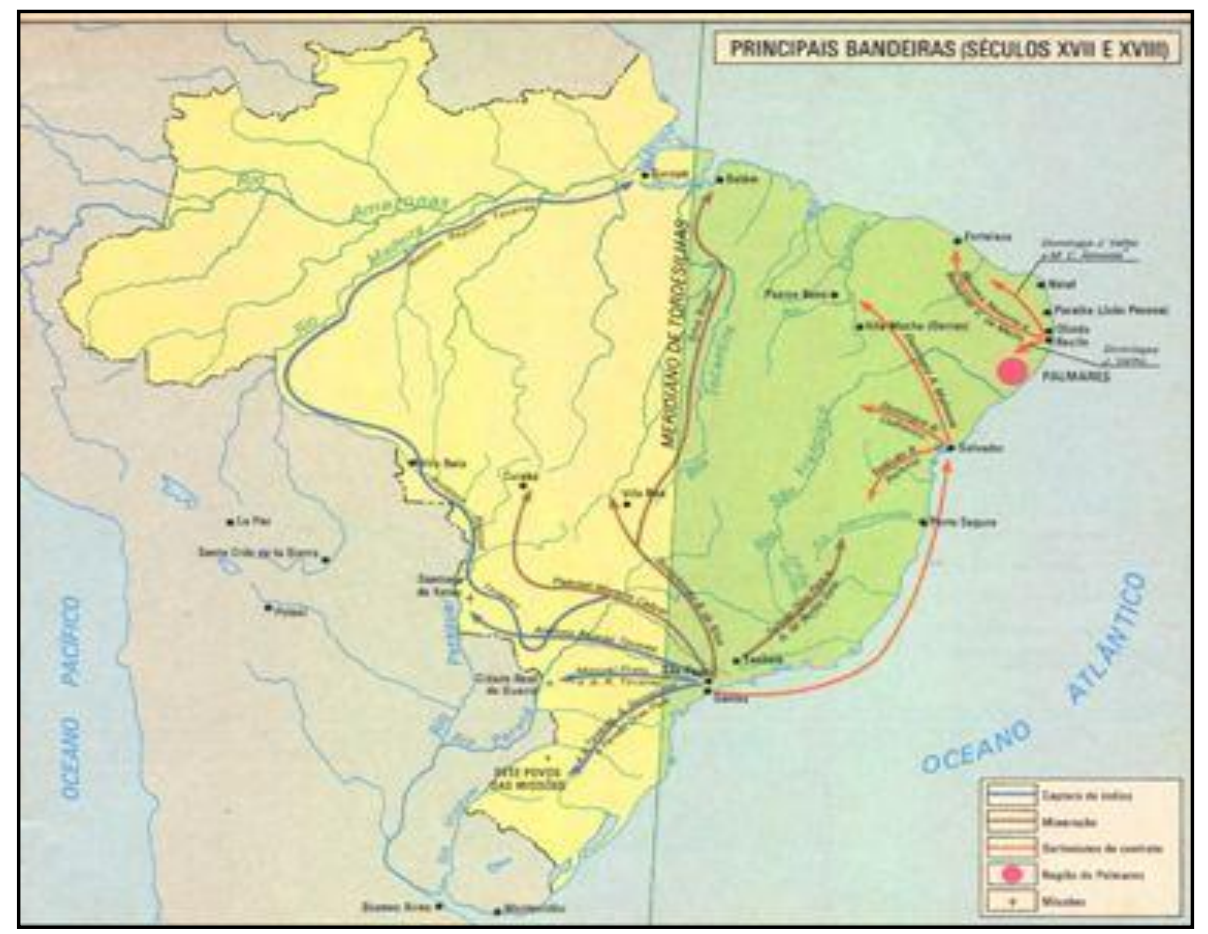

Figura 3: Mapa da entrada e das Bandeiras.

Fonte: www2.mre.gov.br

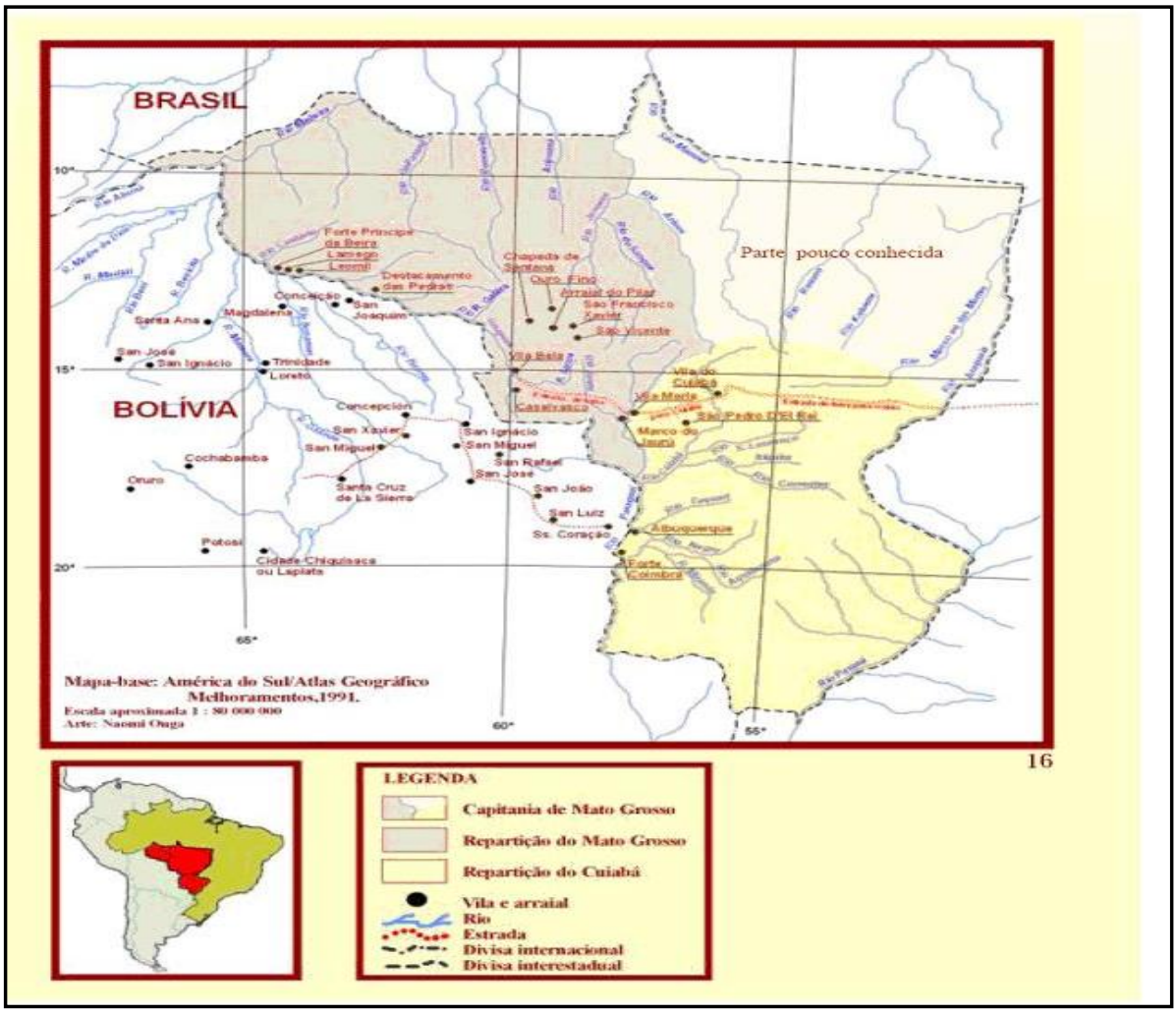

Figura 4: Mapa da Capitania do Mato Grosso.

Fonte:http://www.cefaprojuina.com/portal/images/stories/amapadocuiaba.jpg 
Por volta de 1765 houve um aumento da ameaça na fronteira por parte dos castelhanos no sentido de se apoderarem da zona ribeirinha do Guaporé, incentivados pelo vice-rei do Rio da Prata (atual Paraguai) que era subordinado ao reino da Espanha. Assim, a partir de 1772 os Governos que sucederam a Capitania de Mato Grosso trataram-na com base no uti possidetis para consolidar os limites das fronteiras das colônias no oeste, com a posse e a conquista de novos territórios, assegurando o domínio da margem direita do rio Paraguai, sempre reforçando as defesas das pequenas fortificações e povoações existentes nos limites da Capitania.

Por volta de 1819 o governador Francisco de Paula Magessi Tavares de Carvalho solicitou a mudança da sede de Governo para Cuiabá, pela insalubridade de Vila Bela, onde ocorreram várias febres endêmicas, e por Cuiabá ser bem mais urbanizada e saneada, com este ato ele desagradou à população, assim como, também, as tropas, a nobreza e o clero, que se juntaram e formaram um movimento que depôs o Governador. Eles elegeram um representante do povo para informar a D. Pedro I, príncipe regente do Brasil. Nesse período a capitania estava submetida a uma dualidade governamental, sem resolver esse conflito, quando chegou a noticia da proclamação da independência e D. Pedro I como imperador, tal fato foi muito comemorado na capitania já que os dois governos apoiavam D. Pedro I acalmaram-se os ânimos e está passou a ser a Província do Mato Grosso com um só governo.

A partir desse momento histórico a Província do Mato Grosso, tentou se recuperar das turbulências que ocorreram no tempo da capitania, e seu primeiro presidente, José Saturnino da Costa Pereira, além de ter tido esta árdua tarefa de organizar a província, também se preocupou com o isolamento da província. Ele insistiu bastante na construção de um arsenal de marinha que permitiu uma melhor comunicação com o resto do Império, estabelecendo, também, comunicação com São Paulo e com o Norte do Império pela navegação do rio TelesPires, Araguaia e Guaporé. É neste período que evidenciando o que Gonçalves (2001) denominou como padrão de ocupação amazônico, "rio-várzea-floresta", pois o rio teve uma participação significativa para a formação deste território.

A província permaneceu com os mesmos limites territoriais da capitania, e a insatisfação do Paraguai, também, permaneceu. Nota-se que os presidentes da província sempre se preocuparam com a segurança e reforçavam as guarnições nas fronteiras. Mas é neste momento que explode a guerra do Paraguai (1864-1870), quando o Paraguai prende o Brasileiro Marques de Olinda e invade o sul do Mato Grosso. A falta de conhecimento da região, o relevo acidentado, e o relevo alagado do pantanal dificultaram a guerra. Apesar disso o Brasil ganhou a guerra configurando de vez o território da província do Mato Grosso. 
No Pós Guerra a economia da província ficou um pouco debilitada, e com a abolição da escravatura, pela princesa Isabel, houve uma crise aguda na economia, pois era basicamente da lavoura e do pastoreio, com mão de obra basicamente escrava, que a produção era sustentada. Assim, no fim do século XIX para inicio do século XX, buscou-se estruturar as cidades e recuperar a economia com a introdução de novas atividades como a produção de borracha e a produção de erva mate.

Já no período republicano nota-se que entre as principais atividades econômicas que se desenvolveram no agora Estado do Mato Grosso, no inicio do século XX, estavam à produção de borracha e a poaia na região norte do Estado, além da presença de usinas de açúcar em sua parte central, enquanto na parte sul do Estado predominou a criação de gado e do cultivo da erva-mate, observar a figura 5.

Figura 5: Mapa das principais atividades econômicas no espaço Mato-grossense: Inicio do Século XX.

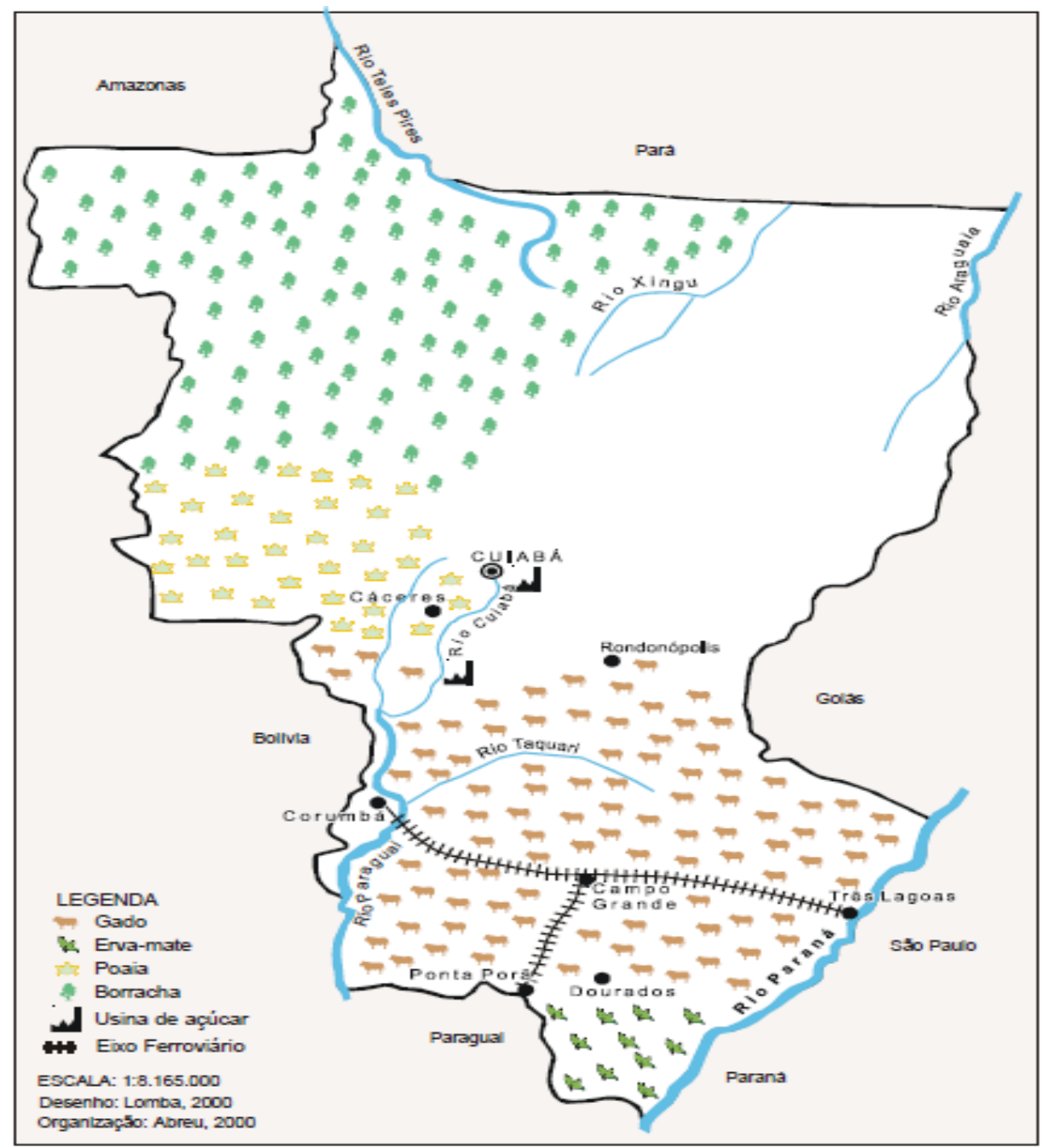


Nota-se que é neste período que irão surgir os fatores a favor da divisão do Estado. Os fatores que alegados para a divisão do Mato Grosso foram: a diversidade e extensão territorial que dificultava o desenvolvimento do Estado de forma igualitária e, também, o jogo político existente para uma proposta de divisão estadual, este segundo pôde ser observado durante a Revolta Constitucionalista que durou 90 dias e proporcionou à parte sul criar e instalar um governo próprio, e no fim da década de 1970 e inicio da década de 1980 o presidente Ernesto Geisel assinou a Lei Complementar $\mathrm{n}^{\mathrm{o}} 31$ dividindo Mato Grosso e criando o Estado de Mato Grosso do Sul. A data virou marco de independência da Região Sul em relação à capital Cuiabá.

Observa-se que a divisão do Mato Grosso em dois Estados ocorreu por meio de um processo demorado, em que foram levados em consideração aspectos socioeconômicos, políticos e culturais. Enquanto o Sul do Estado tentava a divisão, o norte endurecia e barrava as intenções sulistas. O processo de ocupação e consolidação territorial tanto da parte norte quanto do sul evidenciou diferenças e semelhanças que serviram de justificativa para a divisão estadual.

Deve-se atentar para o fato de que a região Centro-Oeste ainda não era considerada uma região consolidada do ponto de vista do desenvolvimento capitalista nacional, ou seja, a região era considerada como um espaço de transição entre o desenvolvimento capitalista consolidado no Sudeste e a emergente fronteira de recursos da Amazônia. Este espaço matogrossense seria o ponto de direcionamento para a efetivação de uma "especialização" e a "descentralização" das ações de planejamento do governo brasileiro, onde para o Estado do Mato Grosso do Sul definiu-se o aprofundamento do processo agroindustrial com a possibilidade de atrair unidades industriais para efetivar a desconcentração industrial, por sua vez o Estado do Mato Grosso permaneceu no conceito de "vazio", para o qual se incrementou investimento em ocupação, passando o território do Mato Grosso a fazer parte das áreas de incentivos da SUDAM.

\footnotetext{
Ao elaborar políticas para a incorporação dos cerrados ao processo produtivo, o Estado assumia a condição de indutor do desenvolvimento capitalista, desenvolvendo ações diretas para a ocupação do território, a exemplo da abertura das grandes vias. A terra barata facilitou os investimentos, os incentivos da SUDAM e as linhas especiais de crédito atraíram os investidores, principalmente do sul do Brasil (BERNARDES, 2007, p.3)
}

Assim, as políticas de colonização, ocupação e desenvolvimento do Mato Grosso podem ser notadas a partir de projetos do governo federal que tinham como objetivos o desenvolvimento do Estado. Dentre estes projetos de abertura de grandes vias podemos 
destacar implantação e pavimentação da BR-163. Implantaram-se distritos industriais em Cuiabá e ocorreu a modernização da agricultura e ocupação dos cerrados pela monocultura da soja, que adquiriu uma grande importância para a economia do país e do Estado, tornando-se um dos principais produtos de exportação.

\section{2 - A chegada e o avanço da soja no Estado do Mato Grosso}

Para iniciarmos qualquer análise da penetração das terras agricultáveis e da potencialidade produtiva, dos rearranjos organizacionais aplicados a inserção de commodities agrícolas no território do Estado do Mato Grosso, no que corresponde a soja, torna-se necessário mencionar que a soja penetra no território mato-grossense vindo da parte sul do Brasil, na qual chega como curiosidade botânica, inserindo-se o seu cultivo a partir da segunda década do século XX, com os imigrantes japoneses, Bernardes et al (2003).

Nota-se que a inserção do cultivo da soja no sul do Brasil é favorecida em um primeiro momento por aspectos físicos, como o clima, a geologia, o relevo, além da disponibilidade de terras e proximidade dos ainda tímidos corredores de exportação de futuras commodities agrícolas, dentre outros fatores que fazem o pioneirismo e o tradicionalismo do cultivo da soja nos Estados do sul do Brasil, a exemplo de Rio Grande do Sul e Paraná, no limiar da década de 1940. A conquista de novas áreas, potencialmente cultiváveis, ganha ascensão a partir da década de 1960 e 1970, quando temos ainda uma tímida produção sojeira adentrando o bioma do cerrado brasileiro.

\footnotetext{
Segundo o IBGE, já em 1940 esta região produziu 1529 T. Em 1960, dos 216033 T produzidos pelo país, $214759(99,4 \%)$ correspondiam à região sul, e o Centro-Oeste aparece no total nacional, embora com uma parcela ínfima (101T, dos quais 98\% corresponde ao Mato Grosso). Em 1980, o Centro-Oeste é a segunda região brasileira produtora de soja, com 1.509.967 T (10,9\%) (...) Entretanto em 2000, a região Centro-Oeste lidera o ranking nacional da produção de grão (SILVA, 2005, p. 3)
}

É fato que o avanço do cultivo da soja expande a fronteira agrícola brasileira, iniciando, como já mencionado o aumento da produção de commodities agrícolas. A soja a partir deste contexto ganha espaço na produção e na balança comercial brasileira, fazendo com que se tenha certa preferência, mediante a valorização do produto no mercado internacional, isso faz surgir agentes/atores que passam a articular e dinamizar este complexo produtivo sojeiro, necessitado de articulações logísticas e infraestruturais para que a dinâmica da fronteira possa continuar a sua mobilidade, o seu avanço e mantendo, assim, o seu crescimento na formação de um novo ciclo econômico brasileiro: "o ciclo da soja". 
A maior aceleração do domínio do território conquistado pela soja se dá a partir da década de 1970 com as políticas de colonização dos governos militares, na tentativa de minimizar as tensões sociais brasileiras e ocupar para futuramente explorar as potencialidades de regiões pouco dinamizadas economicamente. O Estado do Mato Grosso entra neste cenário, principalmente com a abertura de eixos rodoviários importantes na região, a exemplo da BR-163, ligando Cuiabá à Santarém. Deste modo surgiu o fenômeno da "venda de lotes de terras para colonos que perderam a capacidade de competição frente à mecanização da agricultura nos Estados sulistas (em especial do Paraná e do Rio Grande do Sul)" (SILVA, 2005, p. 2).

A produção de soja tem se expandido pelo território brasileiro, principalmente ao longo do Estado do Mato Grosso, observe no mapa da figura 6 a quantidade produzida de soja no Brasil no ano de 1996.

Observe no mapa da figura 7 como ocorreu o aumento da quantidade produzida de soja em 2006, 10 anos depois, percebe-se um aumento expressivo.

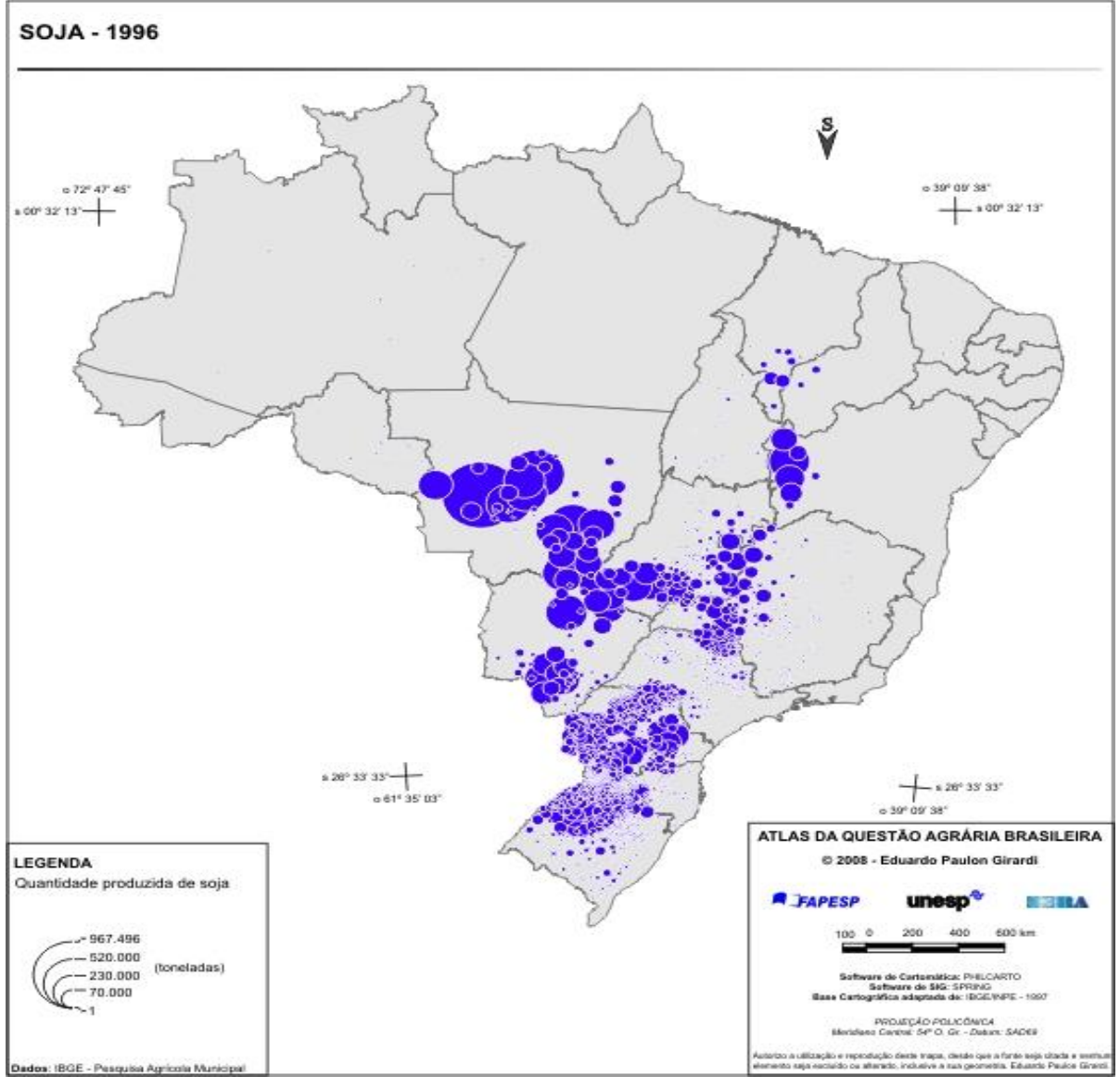

Figura 6: Mapa da quantidade produzida de soja em 1996.

Fonte: INCRA 


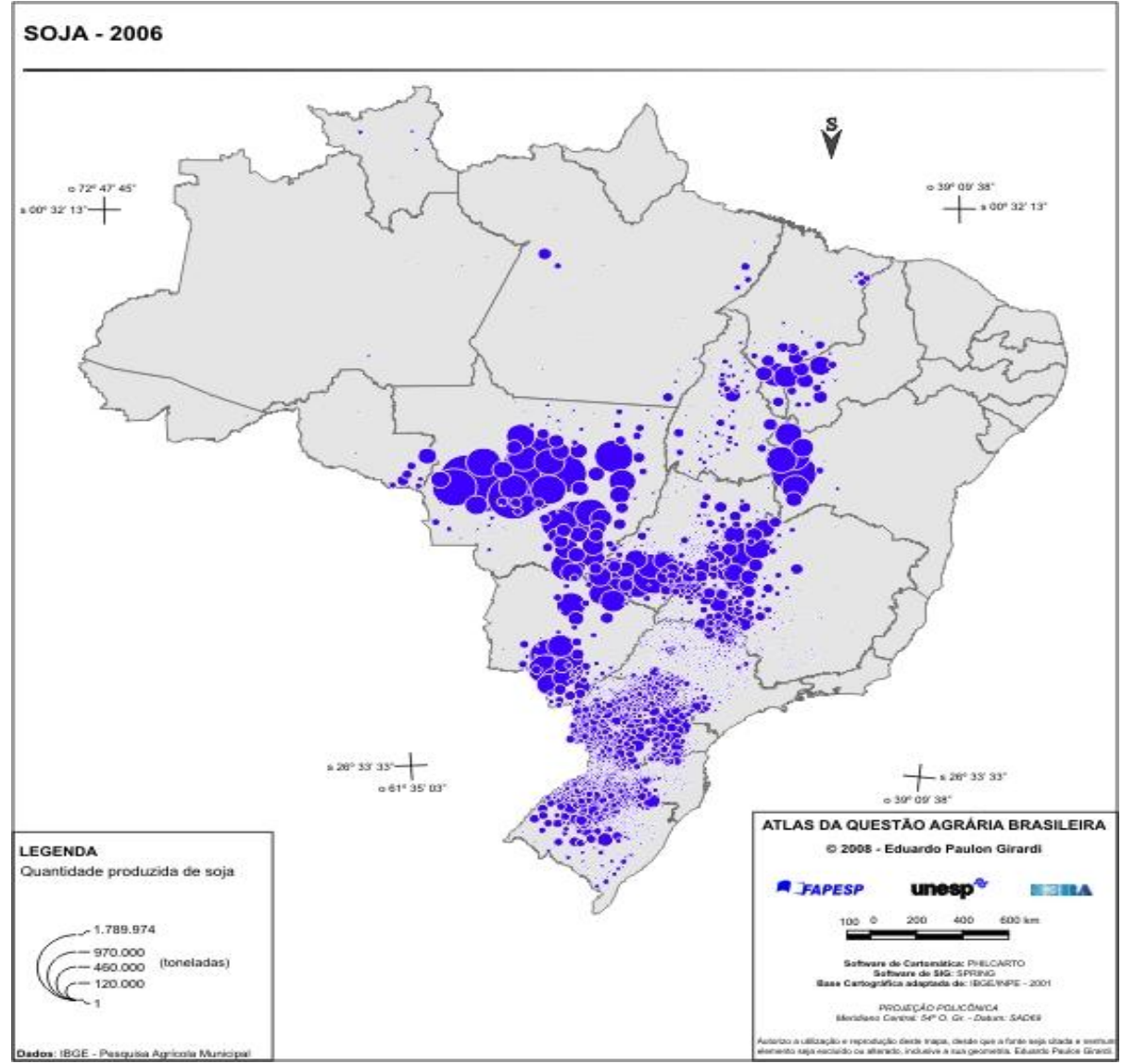

Figura 7: Mapa da quantidade produzida de soja em 2006.

Fonte: INCRA

\section{1 - A logística e a Infraestrutura do complexo sojeiro no Estado do Mato Grosso}

O sucesso do complexo sojeiro ocorre principalmente devido às articulações na qual os diferentes agentes públicos e privados convergem em sintonia para a maximização produtiva. Sendo estas articulações mais aceleradas a partir da política de integração nacional nos governos militares, com maior volume após a década de 1970, traduzindo a necessidade de alcance de um superávit primário. O poder público, nas suas várias instâncias favorece a logística e a infraestrutura básica para a produção de commodities agrícolas, como é o caso da soja.

O que de fato se esperava ou espera-se da capacidade produtiva e do aproveitamento agrícola da região se traduziu na infraestrutura e na logística deficitária durante o avanço da produção sojeira, com algumas deficiências apresentadas, principalmente no âmbito do escoamento da produção. "A expansão das áreas agrícolas, que impulsionou a formação de um novo arranjo espacial dos setores produtivos, não foi acompanhada pela expansão do setor de transportes (...) por um sistema viário eficiente" (OJIMA, 2005, p.1). As necessidades 
surgem em uma velocidade superior às soluções encontradas e eficiências para solução dos problemas de logística que no domínio econômico esta sendo entendida como a

preparação continua dos meios (...) para a competição que se expressa num fluxograma de um sistema de vetores de produção, transporte e execução, ou seja, um sistema de ordenamentos de lugares e regiões privilegiados, condições adequadas de transporte, comunicações e energia (BECKER, 2004).

O Estado do Mato Grosso apresenta entre outras precariedades, decorrentes do crescimento populacional principalmente um crescimento oriundo das correntes migratórias e da rápida expansão agrícola (considerando o seu processo histórico de formação do território).

De certa forma "pode-se considerar que um dos pontos a serem superados seria as barreiras ligadas à infraestrutura enfrentada pelos segmentos de logística e transportes das commodities agrícolas" (BARROS; MODENESI; MIRANDA, 1997). Além disso, deve-se pensar em mecanismos para minimizar os impactos ambientais e socioeconômicos, pois o que se percebe é que os sistemas de objetos (SANTOS, 2002), que estão se expandindo no território para viabilizar uma maior fluidez para os investimentos produtivos, tem proporcionado "uma verdadeira dispersão espacial da produção, acirrando a divisão social e territorial do trabalho e as trocas intersetoriais, resultando em diferentes arranjos produtivos em todo o país, tanto no campo como nas cidades" (ELIAS, 2006, p. 281).

\section{Mas então de que maneira a soja se utiliza dos transportes para exportação?}

A soja necessita de várias soluções para melhorar a logística de transportes, que só será efetivada com um aproveitamento mais adequado dos fatores físicos e hidrológicos da região considerando modais que possam dar uma melhor possibilidade de escoamento da produção como as hidrovias ou talvez ferrovias para que a dualidade custo/benefício possa ser mais bem analisada pela indústria sojeira. No entanto, as maneiras com que os diferentes modais estão se manifestando ainda é muito tímida, com exceção do rodoviário que é o mais utilizado e até mesmo, dependendo da região, o único aproveitado, mesmo com sérias deficiências que vem se resolvendo com articulações infraestruturais entre o complexo empresarial sojeiro e o poder publico estadual e federal. Nota-se que a expansão do sistema viário foi muito significativa se comparado a períodos anteriores, havendo assim uma reconfiguração no padrão de organização do espaço, pois as rodovias passam a ter maior valor estratégico do que os rios, evidenciando assim o que Gonçalves (2001) chamou de segundo padrão de organização do espaço o "estrada-terra firme-subsolo". 
È importante compreender a apropriação dos modais de transportes por esta logística e a maneira com que ela se manifesta Silva (2005), além disso, devemos compreender as articulações e os conflitos de interesse entre os atores do complexo sojeiro dentro do Estado do Mato Grosso. Essas articulações pressionam o Estado no sentido de aplicar uma política desenvolvimentista na criação e manutenção de infraestruturas principalmente no eixo rodoviário da área de influência da BR-163 (Cuiabá-Santarém) para o escoamento da produção sojeira, no sentido de minimizar os custos com transportes e "fortalecer" grupos empresariais que dinamizam a logística do setor.

Assim nota-se, "que com o asfaltamento da BR-163, a CARGILL será diretamente beneficiada" (SILVA, 2005, p.8), porque seu acesso ao porto de Santarém será otimizado.

Podemos perceber que as grandes corporações controlam a produção de commodities gerenciando a infraestrutura, a armazenagem e a compra e venda de produtos. Como nenhuma delas produz soja, mas, terceiriza a produção (exceção feita ao grupo MAGGI), a terra não é condição crucial para expansão da empresa, portos e estradas assumem maior valor estratégico (SILVA, 2005, p.8).

Projetos de infraestruturas estão sendo realizados no território mato-grossense, é o caso do asfaltamento da BR-163, observe na figura 8 na pág. 14, o mapa da área de influencia da BR-163. Nota-se que

A partir dos anos 90, a BR-163 mato-grossense vem constituindo uma das principais fronteiras de expansão da agricultura moderna no cerrado, concentrando a maior produção de grãos nos municípios de Sorriso, Lucas do Rio Verde, Nova Mutum, Nova Ubiratã, Diamantino e Tapurah (BERNARDES, 2010, p. 3 ).

Estes projetos estão virando uma realidade para a produção sojeira, com a aprovação de um pacote bilionário do Governo Federal, fazendo expandir os cultivares de soja cada vez mais para a Amazônia. A hidrovia Tapajós- Teles Pires, também, poderá ganhar dinâmica neste pacote de infraestruturas. Tudo para aumentar a reprodução do capital proveniente desta commoditie agrícola, pois

No conjunto do estado, os espaços da soja apresentam-se como um lócus
privilegiado de processo de homogeneização a partir do capital produtivo,
expressando que certos espaços encontram-se submetidos a fluxos seletivos de
modernização que transformam antigos espaços em espaços de administração de
novas tendências (BERNARDES, 2008, p.364). Como se pode observar é isso que está ocorrendo no campo brasileiro, em especial no Estado do Mato Grosso. 


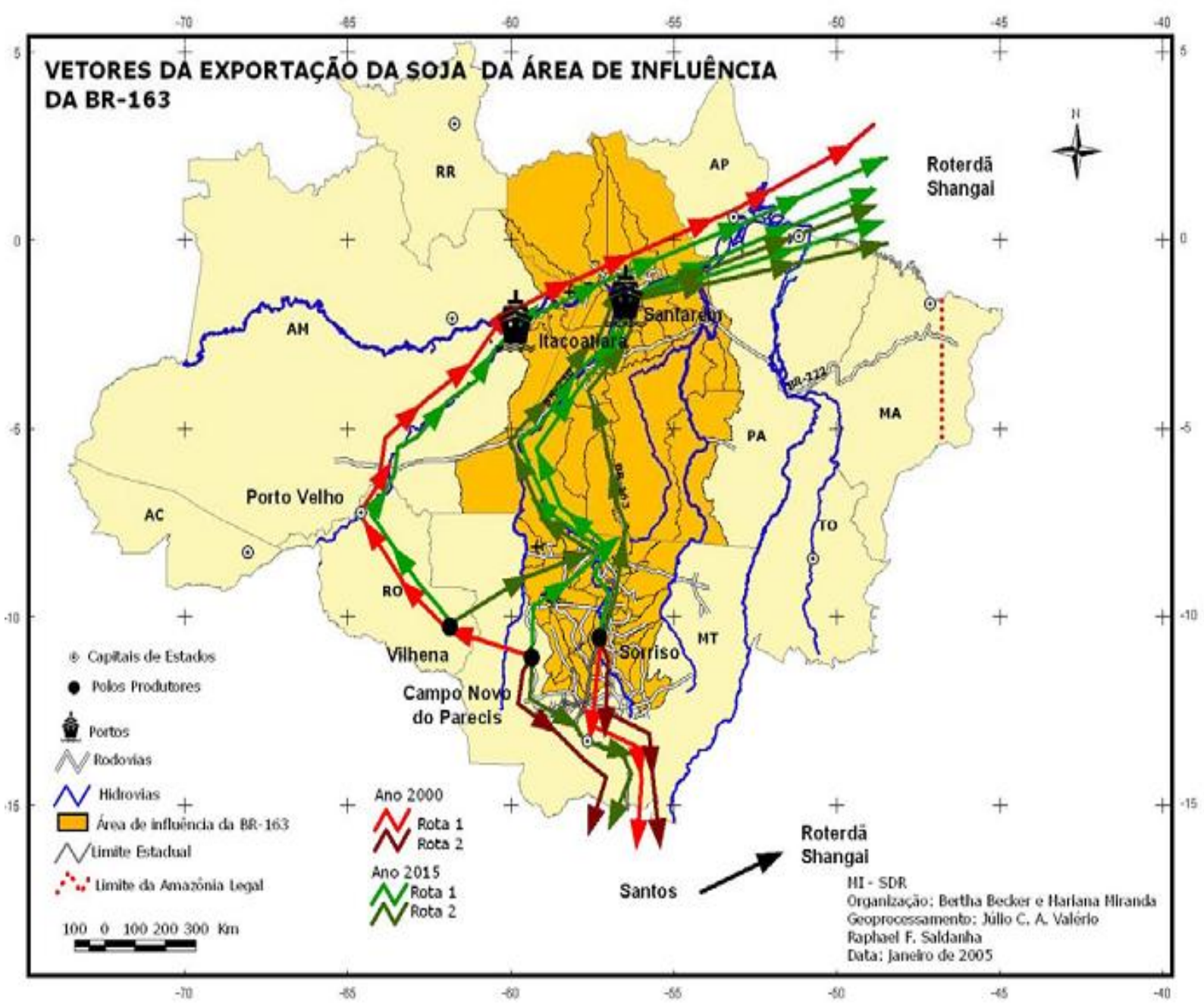

Figura 8: Mapa da área de influência da BR-163.

Fonte: Silva (2005)

Observa-se que nos últimos vinte anos a soja tem sido uma das culturas que tem apresentado o maior progresso dentro do contexto nacional. Isso foi possível graças a vários fatores que vão desde condições naturais à melhoria de infraestrutura e logística.

Entretanto cabe ressaltar que a soja tem provocado profundas transformações no território. Tais transformações estão ligadas ao surgimento e aumento de impactos ambientais e socioeconômicos.

Ao tratarmos sobre os impactos ambientais provocados pela atividade sojeira vale ressaltar que o Estado do Mato Grosso, assim como outros Estados da Amazônia Legal, “oferece condições físicas para a expansão deste tipo de lavoura, tanto em áreas de cerrado ou de transição cerrado-floresta, quanto em zonas de campo, ou ainda em terras desmatadas e áreas degradadas pela pecuária" (PASQUIS e VARGAS, 2009, p.4). 
Entretanto como mencionado anteriormente, a soja tem provocado impactos no território. Alguns destes impactos ambientais são: o aumento do desmatamento, principalmente no bioma cerrado, observar na figura 9, "a degradação do solo e agravamento do quadro critico da disponibilidade de recursos hídricos, isso em decorrência da irrigação". (BRASIL, 1995 apud BARRETO, 2004, p. 5).
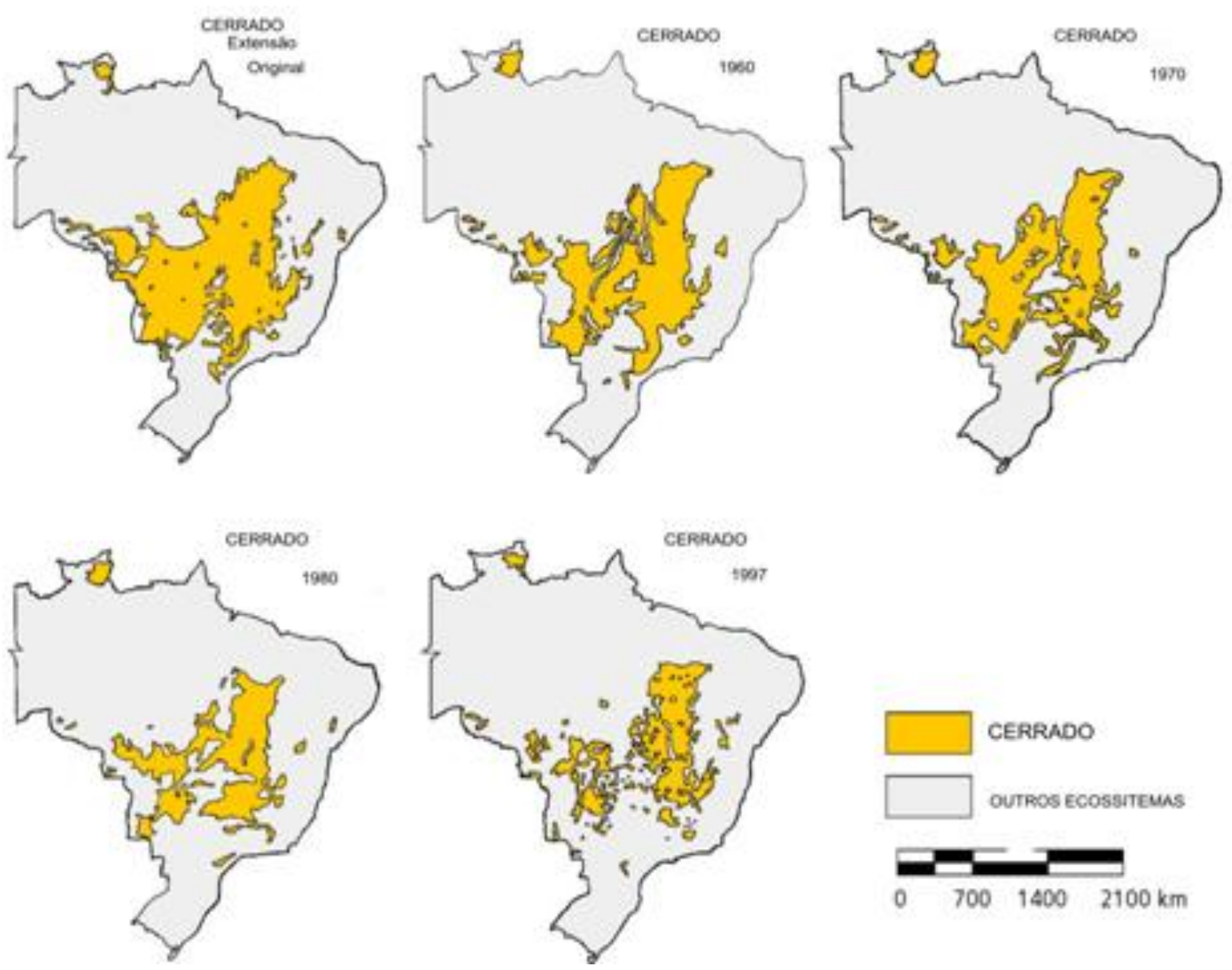

Figura 9: Devastação do bioma cerrado ao longo de décadas.

Fonte: Oliveira (2009)

Outros impactos visíveis são as "erosões dos solos, o assoreamento de rios, a eutrofização dos rios, o nível de cobertura e perda gradual da fertilidade dos solos, fogo disseminado pelos minitornados que assolam a região ou pelos próprios equipamentos usados na colheita” (MUELLER e BUSTAMANTE, 2002 apud PASQUIS E VARGAS, 2009, p.11). São estes equipamentos, ou melhor, esta mecanização que chega junto com a soja que tem causado, também, impactos socioeconômicos, principalmente, para os pequenos produtores, é o que veremos mais adiante. 
Nesse sentido nota-se que a "larga escala da produção da soja representa uma enorme pressão sobre os recursos naturais e ecossistemas da região" (WWF, 1995 apud PASQUIS E VARGAS, 2009, p.11).

Mas há de se destacar que o aumento dos impactos ambientais no Estado do Mato Grosso é decorrente, também, de "políticas públicas que tem estado sujeitas a concepções contraditórias" (BURSZTYN, 2001 apud PASQUIS e VARGAS, 2009, p.7), pois quando se fala em políticas públicas ambientais, observa-se que:

\footnotetext{
As formulações se fazem através de propostas técnicas periféricas ao desenho das outras políticas públicas, o que se tem mostrado insuficiente. Em outra vertente o meio ambiente é visto como uma oportunidade para captar recursos (...). Dessa forma, o ambiente é considerado restritivo ou lucrativo, e a sua incorporação ao desenho do próprio processo de desenvolvimento e dos seus resultados fica comprometida. (PASQUIS e VARGAS, 2009, p.8).
}

Ressalta-se, também, que estas políticas ambientais apresentam uma série de problemas que já começam desde sua formulação, pois "elas são elaboradas e implementadas de cima para baixo" (PASQUIS e VARGAS, 2009, p.8). Compreende-se, ainda, que nos últimos anos a logística criada pela soja tem buscado se ampliar e isso é de certa forma preocupante, pois "a abertura de novas estradas, ferrovias e hidrovias, possibilitada pela implantação dos corredores de exportação, pode ameaçar as poucas áreas do cerrado ainda preservadas e, consequentemente, a riqueza biológica desta região" (BARRETO, 2004, p.6)

\section{Dessa forma seria possível pensar alternativas para que o cerrado não venha a desaparecer em poucos anos?}

Algumas alternativas possíveis seriam, por exemplo, "o plantio direto e a rotação de culturas" (HERNANI, 2002 apud BARRETO, 2004, p.5). São sistemas que estão crescendo na região do cerrado, principalmente em Mato Grosso.

No ano de 2003, o município de Sorriso (MT), sediou o sétimo Encontro do Plantio Direto no Cerrado, no qual foram mostrados os benefícios que este tipo de plantio proporciona. Um exemplo desses benefícios é "quando estas tratam da palhada como uma alternativa de cobertura do solo, que tem sido importante para a fixação do oxigênio e também para a quebra do impacto da chuva sobre o solo" (TOMAZIN e ROSSETTO, 2005, p.10).

Desse modo nota-se que a agricultura sustentável passa a ganhar destaque, já que esta não se preocupa somente com o aspecto econômico, mais também com o meio ambiente Tomazin e Rossetto (2005). 
É inegável que a soja foi/é uma das culturas que apresentou um crescimento expressivo no cultivo e no segmento agroindustrial, isso tem justificado a importância econômica que esta atividade tem proporcionado ao país ao longo destes últimos anos.

Entretanto, cabe ressaltar que apesar da soja ter proporcionado uma melhoria da infraestrutura viária e da urbanização das cidades, ela também causou o aumento dos impactos socioeconômicos não só nas cidades, mais principalmente, no campo, como se já não bastasse os impactos ambientais.

Verifica-se que os impactos socioeconômicos "são resultantes do modelo através do qual foram implantadas as culturas no Brasil, inclusive a soja” (BARRETO, 2004, p.3). Temse observado que os produtores familiares estão sendo excluídos da atividade sojeira, à medida que muitos são expulsos de suas pequenas propriedades para dar lugar aos grandes latifúndios, além disso, tem ocorrido uma fraca geração de empregos, de produção de alimentos e uma alta concentração da posse da terra. Este modelo no qual observamos a modernização dos processos produtivos, juntamente com a presença dos latifúndios e da produção patronal, ficou conhecido como modernização conservadora (EHLERS, 1994 apud BARRETO, 2004).

A soja, por ser um tipo de agricultura altamente mecanizada, provocou uma forte liberalização da mão-de-obra do campo, isso ocasionou migrações. Como conseqüências destas migrações houve uma "ampliação da violência e dos conflitos e o incremento da urbanização que trouxe consigo problemas de desemprego, subemprego e miséria nas cidades do Norte e Centro-Oeste" (MUELLER, 1992 apud BARRETO, 2004, p.4).

E esta urbanização que se intensificou a partir da modernização da agricultura resultou na criação de várias cidades no Estado do Mato Grosso como Sinop (já mencionado), Sorriso, Alta Floresta, Colíder, entre outras. Estas cidades modificaram-se para atender as demandas do campo, é neste contexto que as ações aplicadas sobre o território irão causar a construção dos objetos que a atividade sojeira necessita.

É notório como “a implantação da agricultura moderna proporcionou um duplo processo de re-organização sócio-espacial, pois o campo reestruturou-se como local da produção mecanizada e as cidades equiparam-se para atuar como suporte para a efetivação desse processo" (ROMANCINI; RODRIGUES; SANTOS, 2006, p.3 e 4)

É inegável o papel que a soja exerceu no processo de urbanização de algumas cidades, entretanto é também inegável que ela foi/é geradora de mudanças sejam ambientais, sejam mudanças nas estruturas socioeconômicas urbanas. 
Desse modo percebe-se que a sojicultura provocou/provoca impactos socioeconômicos não somente no campo, mas também nas cidades, pois como citado anteriormente, grande parte destes pequenos agricultores que migram para as cidades (êxodo rural), acabam se inserindo em subempregos e no mercado informal, fortalecendo assim o circuito inferior da economia, (SANTOS, 2004).

\section{Considerações finais}

Ao longo deste trabalho pode-se perceber que a formação do território mato-grossense foi acompanhada por transformações socioespaciais que foram decorrentes, em parte, das atividades econômicas que se desenvolveram nesta região.

Se num primeiro momento tivemos a mineração e a pecuária como principais atividades que dinamizaram a região, atualmente é percebido que este papel tem sido desenvolvido pela atividade sojeira, que tem proporcionado a abertura de novos corredores de exportações, que servem para uma melhor ampliação do capital. Nota-se assim que o Estado passa a criar infraestruturas que viabilizam o escoamento da produção fazendo com que a soja ganhe uma valorização maior.

No entanto compreende-se que esta atividade tem causado uma série de transformações no espaço sejam elas ambientais e socioeconômicas, pois esta atividade é um tipo de agricultura altamente tecnificada. Tem-se observado que ela não tem proporcionado grandes avanços para os pequenos produtores e camponeses, pois "A modernização da agricultura e as históricas questões fundiárias serviram de base para a expulsão de camponeses" (SILVA, 2005).

Cabe lembrar que esta atividade é importante por gerar divisas para o país, mas é necessário lembrar também, que são necessários que sejam criados mecanismos mais eficientes para que os impactos ambientais e socioeconomicos sejam minimizados. 


\section{Referências}

ABREU, Silvana. Planejamento governamental: a Sudeco no espaço mato-grossense contexto, propósitos e contradições. 2001. 323f. Tese de Doutorado, Universidade de São Paulo. Disponível em: http://lajh.unm.edu/handle/10229/35132- Acessado em: 27/10/2009.

BARRETO, Clarissa de Araújo. Os impactos socioambientais do cultivo de soja. In: Anais do II Encontro da Associação Nacional de Pós Graduação e Pesquisa em Ambiente e

Sociedade, São Paulo, 2004. Disponível em: http://www.anppas.org.br/encontroanual/encontro2/gt/gt05/clarissa_barreto.pdf. Acessado em: 03/11/2009.

BARROS, J. R.; MODENESI, R.; MIRANDA, E. F. de. A agricultura e o custo Brasil. Revista Política Agrícola, Brasília, n. 6, p. 3-4, jan./mar. 1997. Disponível em: http://www.embrapa.br/publicacoes/tecnico/revistaAgricola/rpa-anos-anteriores-1/de-1996-a1999/Rev_Pol_Agr_v6_n1-1997.pdf. Acessado em: 03/11/2009.

BECKER, B. Amazônia: Geopolítica na virada do III milênio. Rio de Janeiro: Garamond, 2004. 168p.

BERNARDES, Julia Adão. Dimensões da ação e novas territorialidades no cerrado brasileiro: pistas para uma análise teórica. Revista NERA - ANO 10, $\mathrm{n}^{\mathbf{0}} 10$ JANEIRO/JUNHO DE 2007.2 Disponível em: http://www4.fct.unesp.br/nera/revistas/10/bernardes.pdf. Acessado em: 17/05/2010.

, Julia Adão. A Estratégia do Capital no Complexo da Soja. In: CASTRO et al.

Questões Atuais da Reorganização do Território. $5^{\text {a }}$ Ed. Rio de Janeiro: Bertrand Brasil, 2008. 470p.

,Julia Adão. Cadeia carne/grãos: novas fronteiras do capital no cerrado da BR-163 mato-grossense - brasil. In: Anais do XI Colóquio Internacional de Geocrítica, Buenos Aires, 2010. Disponível em: http://eventos.filo.uba.ar/index.php/geocritica/2010/paper/viewFile/445/338. Acessado em: 17/05/2010.

BERNARDES, Julia Adão; PEIXINHO, D. M.; SCOPEL, I.; MELO, N. A.. A Reestruturação Espacial e a Interação Entre o Local e o Global: O Exemplo da Soja. Revista Boletim Goiano de Geografia, Goiânia, Vol. 23, $\mathrm{n}^{\circ}$ 1, 2003. Disponível em: http://revistas.ufg.br/index.php/bgg/article/viewFile/4729/3976. Acessado em: 03 /11/2009.

ELIAS, Denise. Novas dinâmicas territorias no Brasil agrícola. In: SPOSITO, Eliseu Savério; SPOSITO, Maria E. B.; SOBARZO, Oscar. Cidades médias produção do espaço urbano e regional. São Paulo: Expressão Popular, 2006. 376p.

GONÇALVES, Carlos Walter Porto. Amazônia, Amazônias. São Paulo: Contexto, 2001.

MARTINS, Demosthenes. Historia do Mato Grosso. São Paulo: V Bícego, [s.d.]. 204p.

INCRA. Mapas da produção de soja no Brasil. Disponível em: http://www.incra.gov.br Acessado em: 10/03/2010. 
OJIMA, Andrea Leda Ramos de Oliveira. Perfil da Logística de Transportes de soja no Brasil. 2006. Revista Informações Econômicas, São Paulo, v. 36, n ${ }^{\circ} 1$, Janeiro de 2006. Disponível em: ftp://ftp.sp.gov.br/ftpiea/publicacoes/tec2-0106.pdf-. Acessado em: 03/11/2009.

OLIVEIRA, Ariovaldo U. de. A contra reforma agrária: a regularização fundiária na Amazônia legal e a MP 458 (lei no 11.952, de 25 de junho de 2009) (apresentação em PowerPoint). In: XII Encontro Paraense de Geografia, Parauapebas- PA, 2009.

PASQUIS, Richard (coord.). O que é a Amazônia: tristes trópicos ou terra de boa esperança? In: __ . As Amazônias - um mosaico de visões sobre a região. Brasília, 2003 (impresso).

PASQUIS, Richard; VARGAS, Gloria M.. A soja em Mato Grosso: determinantes do seu avanço e problemas socioambientais. In: AGUIAR et al. Desenvolvimento Territorial Diretrizes Para a Região BR-163. Brasília: WWF, Brasil, 2009. Disponível em: http://www.dialogos.org.br/arquivo/colecao/ASojaemMatoGrosso.pdf. Acessado em: 03/11/2009.

ROMANCINI, Sônia R.; RODRIGUES, Cleire Oliveira; SANTOS, Ronaldo Benedito dos. Sinop: uma abordagem sobre a dinâmica territorial na Pré-Amazônia Mato-grossense. In: Anais do XIV Encontro Nacional de Geógrafos: A Geografia e a Amazônia no contexto latino-americano: diálogo, práticas e percursos, Rio Branco, 2006.

SANTOS, Milton. O Espaço Dividido. São Paulo: Edusp, 2004. 440p.

Milton. A Natureza do Espaço: técnica e tempo, razão e emoção. São Paulo: Edusp, 2002. 384p.

SILVA, Carlos Alberto Franco da. Grupo André Maggi: corporação e rede em áreas de fronteira. Cuiabá: Entrelinhas, 2003.

Carlos Alberto Franco da. A transnacionalização do grupo André Maggi a partir do cerrado mato-grossense. Revista geo-paisagem (on line), Ano 4, $\mathrm{n}^{\mathbf{0}}$ 7, 2005, Janeiro/Junho de 2005. Disponível em: http://www.feth.ggf.br/Maggi.htm. Acessado em: 17/05/2010.

SILVA, Gabriel Damasceno Bento. Sistemas de Transporte e Logística da Soja na BR163. In: Anais do II Simpósio Internacional de Geografia Agrária, Presidente Prudente, 2005. Disponível em: www4.fct.unesp.br/../Gabriel\%20Damasceno\%20Bento\%20da\%20Silva.pdf. Acessado em: 03/11/2009.

TOMAZIN, Jucilene; ROSSETTO, Onélia C.. Impactos ambientais da agricultura no município de Sorriso- Mato Grosso- Brasil. In: Anais do II Simpósio Internacional de Geografia Agrária, Presidente Prudente, 2005. Disponível em: http://www4.fct.unesp.br/nera/publicacoes/singa2005/Trabalhos/Resumos/Jucilene\%20Lourd es\%20Tomazin_PT_ES.pdf. Acessado em: 03/11/2009. 